\title{
A Newton-Raphson Method Approach to Adjusting Multi-Source Solar Simulators
}

\author{
David B Snyder and David A. Wolford \\ NASA Glenn Research Center, Cleveland, OH, USA
}

\begin{abstract}
NASA Glenn Research Center has been using an inhouse designed X25 based multi-source solar simulator since 2003. The simulator is set up for triple junction solar cells prior to measurements by adjusting the three sources to produce the correct short circuit current, Isc, in each of three AM0 calibrated sub-cells. The past practice has been to adjust one source on one sub-cell at a time, iterating until all the sub-cells have the calibrated Isc. The new approach is to create a matrix of measured Isc for small source changes on each sub-cell. A matrix, A, is produced. This is normalized to unit changes in the sources so that $A x \Delta s=\Delta i_{s c}$. This matrix can now be inverted and used with the known Isc differences from the AM0 calibrated values to indicate changes in the source settings, $\Delta s=A^{-1} \mathbf{x} \Delta \mathbf{i}_{\text {sc }}$ This approach is still an iterative one, but all sources are changed during each iteration step. It typically takes four to six steps to converge on the calibrated Isc values. Even though the source lamps may degrade over time, the initial matrix evaluation is not performed each time, since measurement matrix needs to be only approximate. Because an iterative approach is used the method will still continue to be valid. This method may become more important as state-of-the-art solar cell junction responses overlap the sources of the simulator. Also, as the number of cell junctions and sources increase, this method should remain applicable.
\end{abstract}

Index Terms - aerospace testing, photovoltaic cells, solar power generation, solar simulator, solar cell calibration, space power, space technology.

\section{INTRODUCTION}

Solar simulators have been used for past decades to produce laboratory measurements of single junction solar cells. The spectrum of these sources was not critical as long as the appropriate short circuit current, Isc, was produced by photons illuminating the cell. The solar cell current-voltage, $I(V)$, curve was accurate, and cell performance could be measured and compared. However, to produce accurate $I(V)$ curves for multi-junction solar cells, it becomes critical the correct current be produced on each junction, and a more solar-like spectrum is required.

A triple-source solar simulator was designed and built at NASA Glenn Research Center in 2002-2003 [1]. The simulator is based on a SpectroLab X25, with a dichroic mirror to reflect the visible light $<700 \mathrm{~nm}$ to the solar cell test plane. Two separately powered banks of tungsten lamps provide the infrared portion of the spectrum, with one bank of $1 / 3$ of the tungsten lamps filtered to produce $700-900 \mathrm{~nm}$ illumination. For a triple junction solar cell this arrangement is ideal, as there are three adjustments to control the illumination to the three junctions.

The simulator sources are set to the proper illuminations before testing using sub-cells which have a known calibrated short circuit current, Isc, at air mas zero, AM0. Preferably the sub-cells are the same manufacturer and type as the cells to be measured. In most cases the adjustment of the nearly independently illuminated top and bottom cell can be set up, then the middle cell set which is influenced by all three sources. This cycle is iterated until all junctions are at, or near, usually within $0.2 \%$ of Isc(AM0). This method is time consuming and occasionally difficult, so a new, more reliable method was explored.

The Newton-Raphson method [2] uses the derivative of a function to extrapolate to a solution. For non-linear behavior it can be repeated until the solution is sufficiently accurate. The present approach uses a three dimensional version of this method to converge on a solution where the sub-cells all are illuminated correctly.

\section{METHOD}

The goal of this method is to find the three vector elements $\Delta \mathbf{s}$, the change in source settings, that move the present short circuit current, $i_{s c}$, measurements to $i_{s c}(A M 0)$. For $\Delta i_{\mathrm{sc}}=i_{\mathrm{sc}}(\mathrm{AM} 0)-\mathbf{i}_{\mathrm{sc}}$, a derivative related matrix $\mathbf{A}^{-1}$ must be found where

$$
\Delta \mathbf{s}=\mathbf{A}^{-1} \times \Delta \mathbf{i}_{\text {sc }}
$$

This is accomplished by measuring the responses of $i_{s c}$ to individual source changes, i.e. if

$$
A \times \Delta s=\Delta \mathbf{i}_{\mathrm{sc}}
$$

where $A_{j k}=\Delta i_{j} / \Delta s_{k}$. The matrix $A$ found in this manner can be easily inverted to find $\mathbf{A}^{-1}$ in a spreadsheet operation.

The units of the source vector, s, are not important. Since the responses, $\Delta \mathrm{i}_{\mathrm{j}}$ are divided by the source change, $\Delta \mathrm{s}_{\mathrm{k}}$, the lamp current of the $\mathrm{X} 25$, and the voltages of the power supplies for the infrared lamp banks may be used. In fact we use the current change to a monitor cell in our measurement system to monitor the X25 lamp changes, but care has to be taken in this case to use only the changes due to the X25, because the other power supplies also cause the monitor cell current to change. 


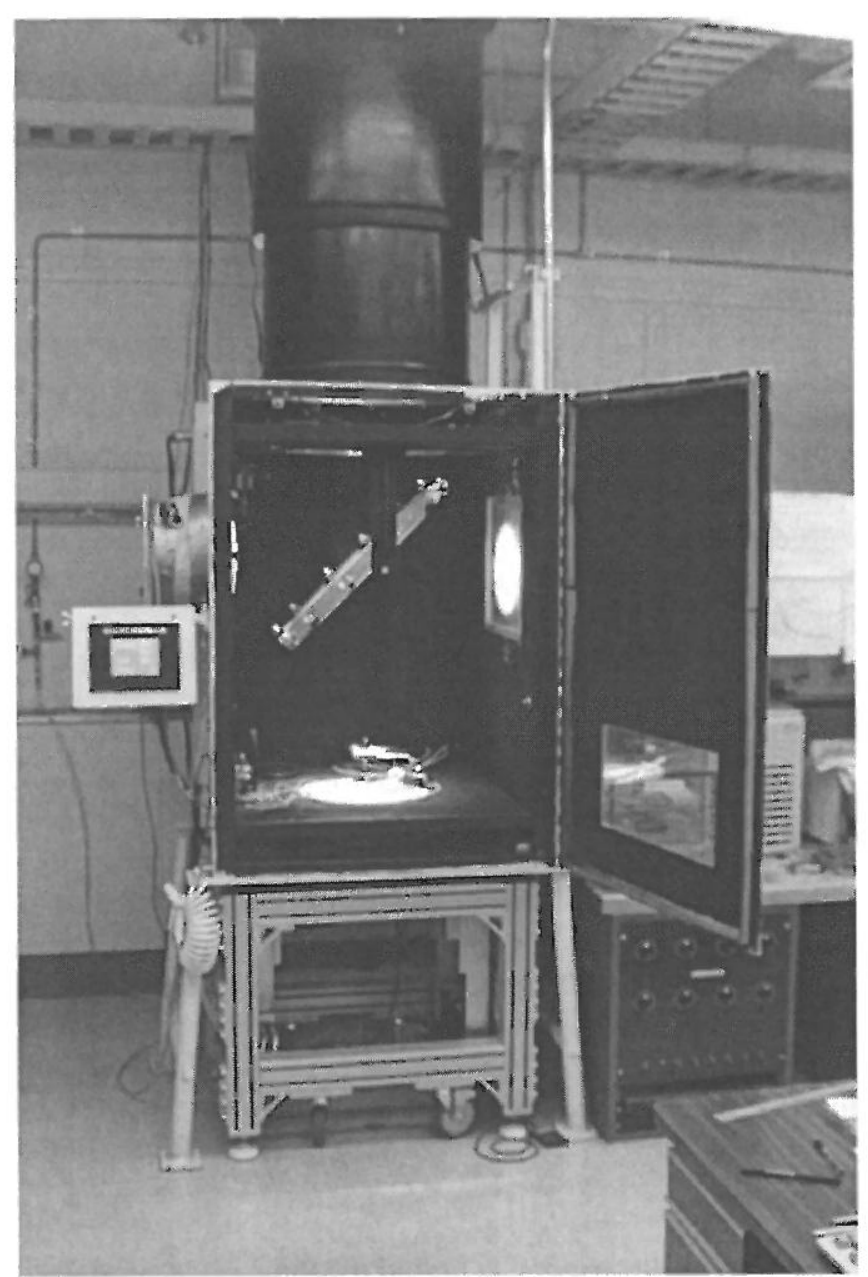

Figure 1. NASA GRC Multi-source Simulator.

Four sets of measurements are made to determine the elements of $\mathbf{A}$, a baseline, then three sets of modified source values. The source changes must be sufficient produce detectable changes on at least one of the sub-cells. Because the X25 source setting is difficult to return to its non-offset value its offset is the initial set of measurements made. The changed top source is measured first. The baseline follows, and then two sets of measurements with the IR sources varied are made. Then, to create the elements of $\mathbf{A}$, the baseline measurements are subtracted from each of the changed source readings, and divided by the source change, $A_{j k}=\Delta i_{j} / \Delta s_{k}$. Table 1 gives an example of the data taken to form the matrix, A. It includes baseline values, planned source changes and the measured Isc values for the changes.

A has to be evaluated only once and does not have to be exact even though solar sub-cell currents cannot be strictly linear with source current and voltage changes. Normally in the Newton method the derivative is evaluated for each new value. Here the effort is reduced by not doing so. Solar subcell currents may not behave strictly linearly with the source changes. However, since the response functions are at monotonic, an increasing source gives an increasing signal. This estimate gives a hint for better values and gives guidance for improving the measurement. It gives a direction, and magnitude of the required change. As one gets close to the correct setting, the indicated adjustments may jump around and oscillate due to errors in A. Reducing the indicated corrections by half may compensate for this effect. If the $\mathbf{A}$ matrix is evaluated near the correct AM0 settings it should be valid for future use. As lamp behavior changes with age, A should continue to function as a sufficient estimate, but can be updated periodically to improve convergence to the optimal settings.

\begin{tabular}{|c|c|c|c|}
\hline Baseline $\mathrm{Isc}_{\mathrm{sc}}$ & $\mathrm{I}_{\text {ref }}$ & $V_{\text {rel }}$ & \\
\hline Top cell & 74.35 & 130.00 & \\
\hline Mid cell & 69.48 & 38.00 & \\
\hline Bot cell & 126.30 & 62.00 & \\
\hline $\begin{array}{l}\text { Matrix source } \\
\text { power offsets }\end{array}$ & $\mathrm{dV}$ & Vref $+d V$ & \\
\hline Top source & -2.00 & 128.00 & \\
\hline Mid source & -1.00 & 37.00 & \\
\hline Bot source & -1.00 & 61.00 & \\
\hline $\begin{array}{l}\text { Data Matrix, } \\
\text { Isca }\end{array}$ & $\begin{array}{c}\text { Top source@ } \\
128.00 \mathrm{~V}\end{array}$ & $\begin{array}{c}\text { Mid source @ } \\
37.00 \mathrm{~V}\end{array}$ & $\begin{array}{l}\text { Bot source } \\
@ 61.00 \mathrm{~V}\end{array}$ \\
\hline Top cell $I_{S c}$ & 72.63 & 75.02 & 75.20 \\
\hline Mid cell $\mathrm{I}_{\mathrm{SC}}$ & 68.67 & 69.03 & 69.25 \\
\hline Bot cell $\mathrm{I}_{\mathrm{SC}}$ & 125.10 & 126.70 & 124.40 \\
\hline
\end{tabular}

Table 1. Data Matrix Elements.

\begin{tabular}{|c|c|c|c|}
\hline Matrix A & $\begin{array}{c}\text { Top source@ } \\
128.00 \mathrm{~V}\end{array}$ & $\begin{array}{c}\text { Mid source @ } \\
37.00 \mathrm{~V}\end{array}$ & $\begin{array}{l}\text { Bot source } \\
\text { (a) } 61.00 \mathrm{~V}\end{array}$ \\
\hline Top cell $\mathrm{I}_{\mathrm{sc}}$ & 0.86 & -0.67 & -0.85 \\
\hline Mid cell $\mathrm{I}_{\mathrm{SC}}$ & 0.41 & 0.45 & 0.23 \\
\hline Bot cell $I_{S C}$ & 0.60 & -0.40 & 1.90 \\
\hline $\begin{array}{l}\text { Inverted Matrix } \\
\qquad \mathbf{A}^{1}\end{array}$ & $\begin{array}{c}\text { Top source @ } \\
128.00 \mathrm{~V}\end{array}$ & $\begin{array}{c}\text { Mid source @ } \\
37.00 \mathrm{~V}\end{array}$ & $\begin{array}{l}\text { Bot source } \\
\text { (a) } 61.00 \mathrm{~V}\end{array}$ \\
\hline Top cell $\mathrm{I}_{\mathrm{SC}}$ & 0.59 & 1.01 & 0.14 \\
\hline Mid cell $I_{s c}$ & -0.39 & 1.34 & -0.34 \\
\hline Bot cell $\mathrm{I}_{\mathrm{SC}}$ & -0.27 & -0.04 & 0.41 \\
\hline
\end{tabular}

Table 2. Matrix and Inverted Matrix Elements. 


\begin{tabular}{|c|c|c|c|c|c|}
\hline $\begin{array}{c}\text { Power } \\
\text { Source (V) } \\
\text { or Junction } \\
\text { ID }\left(I_{S C}\right)\end{array}$ & $\begin{array}{c}\text { Calculated } \\
\text { New Power } \\
\text { Source } \\
\text { Voltage }\end{array}$ & $\begin{array}{c}\% \text { deviation } \\
\text { from Reference } \\
\text { Value }\end{array}$ & Measured I $\mathrm{ISC}_{\mathrm{S}}$ & $\begin{array}{c}\text { Power Source } \\
\text { Voltage }\end{array}$ & Iteration \# \\
\hline Top & 126.55 & 7.287 & 74.35 & 130.00 & 0 \\
\hline Mid & 37.89 & 1.253 & 69.48 & 38.00 & 0 \\
\hline Bot & 64.54 & -2.169 & 126.30 & 62.00 & 0 \\
\hline Top & 126.40 & -0.014 & 69.29 & 127.00 & 1 \\
\hline Mid & 37.36 & 0.772 & 69.15 & 37.90 & 1 \\
\hline Bot & 63.81 & 0.387 & 129.60 & 64.00 & 1 \\
\hline Ton & 12671 & 0144 & 60.40 & 12650 & \\
\hline & 120,11 & 0.144 & 07.40 & 120.50 & 2 \\
\hline Mid & 38.32 & -0.554 & 68.24 & 37.50 & 2 \\
\hline Bot & 63.58 & 0.620 & 129.90 & 63.90 & 2 \\
\hline Top & & 0.058 & 69.34 & 126.70 & 3 \\
\hline Mid & & -0.175 & 68.50 & 38.00 & 3 \\
\hline Bot & & -0.077 & 129.00 & 63.70 & 3 \\
\hline
\end{tabular}

Table 3. Example of iterative power source voltage adjustment

Table 2 shows example of the matrix, $\mathbf{A}$, and its inverse $\mathbf{A}^{-1}$. Table 3 provides an example of the steps followed to reach the desired solar simulator settings. In this case it took three steps to converge to the calibrated currents to within a reasonable error.

\section{CONCLUSIONS}

A Newton-Raphson method of adjusting multi-source solar simulators to AM0 with calibrated sub-cells has been described. When starting near calibration, four to six iterations may produce good settings. A time saving aspect of the method is that the derivative related matrix $\mathbf{A}$ and its inverse $\mathbf{A}^{-1}$ do not have to be evaluated repeatedly throughout the setup process. If $\mathbf{A}$ is evaluated near a completed setup, it may also be used for future adjustments.

This approach to multi-source simulator may be easily extended to four or more sources desirable for the next generations of multi-junction solar cells.

\section{REFERENCES}

[1] P. Jenkins, et al, "Design And Performance Of A Triple Source Air Mass Zero Solar Simulator", 18th Space Photovoltaic Research and Technology Conference, Brook Park, Ohio, September $16-18,2003$, NASA/CP - 2005-213431, pp 134138.

[2] W. H. Press et al, Numerical Recipes in C, The Art of Scientific Computing, $2^{\text {nd }} \mathrm{Ed}$, Cambridge University Press, 1992, section 9.6, pp 379-382. 